\title{
Perencanaan Kegiatan Wisata Pendidikan Dalam Kawasan Geopark Rinjani Lombok Berbasis Daya Dukung Lingkungan (Studi Daerah Aik Berik)
}

\author{
Dwi Hardoyo ${ }^{1}$, Fuad Muhammad ${ }^{1,2}$, Tukiman Taruna1 \\ ${ }^{1}$ Magister Ilmu Lingkungan, Sekolah Pascasarjana, Universitas Diponegoro, Semarang ; email: dyhard98@gmail.com \\ ${ }^{2}$ Departemen Biologi, Universitas Diponegoro, Semarang
}

\begin{abstract}
ABSTRAK
Aik Berik merupakan daerah tujuan wisata yang berada dalam kawasan Geopark Rinjani Lombok. Di daerah ini terdapat situs geologi yang dapat digunakan sebagai sarana pendidikan melalui kegiatan wisata pendidikan bagi anakanak sekolah, namun perlu dilakukan kajian daya dukung lingkungan agar kegiatan tersebut tidak menyebabkan gangguan pada ekosistem dan kenyamanan para siswa dalam melakukan aktivitas juga dapat dipertahankan. Tujuan dari penelitian ini adalah untuk mengetahui nilai daya dukung lingkungan obyek wisata Aik Berik sehingga dapat digunakan untuk merencanakan/menentukan waktu yang tepat dalam melaksanakan kegiatan wisata pendidikan. Metode yang digunakan adalah perhitungan berdasarkan rumus daya dukung lingkungan yang dimodifikasi, yaitu Daya Dukung Fisik (PCC), Daya Dukung Riil (RCC) dan Daya Dukung Efektif (ECC). Pengumpulan data dilakukan melalui observasi/survei lapangan, studi literatur, dan wawancara. Hasil penelitian menunjukkan bahwa Daerah Aik Berik mempuyai nilai daya dukung fisik (PCC) 18.665 orang/hari dan daya dukung Riil (RCC) 3.863 orang/hari. Pada hari minggu daya dukung riil belum terlewati, sekitar 19,9\% dari RCC atau 767 orang/hari. Pelaksanaan wisata pendidikan dapat dilakukan pada hari biasa (Senin-Jumat) dengan cara praktikum bersama atau dengan memanfaatkan alokasi waktu KBM yang dijadwalkan pada akhir sesi KBM.
\end{abstract}

Kata kunci: Geopark Rinjani Lombok, Wisata Pendidikan, Daya Dukung Lingkungan

\begin{abstract}
Aik Berik is a tourist destination within Geopark Rinjani Lombok. In this area there is a geological site that can be used as an education mean through educational tours for school children, but it is necessary to study environment carrying capacity so that these activities do not cause disturbance to the ecosystem as well as maintaining students activity comfort. The aim of this study was to determine Aik Berik carrying capacity that can be used to determine the best times in conducting educational tours. The method used based on modified environment carrying capacity formula calculation, the Physical Carrying Capacity (PCC), Real Carrying Capacity (RCC) and Effective Carrying Capacity (ECC). Data collected through observation/field surveys, literature, and interviews. The results showed that Aik Berik area has value of physical carrying capacity (PCC) 18.665 person/day and the Real carrying capacity (RCC) 3,863 person/day. On Sunday the real carrying capacity has not been reached, approximately 19.9\% of RCC or 767 person/day. Implementation of the educational tour can be done on a weekday (Monday-Friday) by internship activities together or by allocating scheduled time in teaching and learning activities.
\end{abstract}

Keywords: Geopark Rinjani Lombok, Educational Tourism, Carrying Capacity

Cara sitasi: Hardoyo ,D., Muhammad, F., dan Taruna, T. (2016). Perencanaan Kegiatan Wisata Pendidikan Dalam Kawasan Geopark Rinjani Lombok Berbasis Daya Dukung Lingkungan (Studi Daerah Aik Berik). Jurnal Ilmu Lingkungan,14(2),103-107, doi:10.14710/jil.14.2.103-107

\section{PENDAHULUAN}

Salah satu bentuk kontribusi terhadap tujuan Agenda 21, yaitu agenda pengetahuan untuk lingkungan hidup dan pembangunan menuju abad dua puluh satu adalah perlindungan dan pengembangan keragaman geologi yang mempunyai makna sebagai warisan geologi melalui Taman Geologi atau Geopark (Kusumabhrata \& Suwardi, 2012). Geopark merupakan konsep pembangunan berkelanjutan yang di dukung oleh UNESCO dengan memfasilitasi terbentuknya organisasi yang mampu menampung negara-negara anggota melalui Global Geopark Network (GGN).

Setiap negara yang mengusulkan geopark Nasionalnya untuk menjadi anggota GGN harus memenuhi beberapa kriteria yang telah ditetapkan oleh UNESCO. Salah satu kriteria GGN-UNESCO adalah Geopark harus mengkomunikasikan pengetahuan geosains /geologi dan konsep-konsep lingkungan kepada masyarakat. Selain itu, Geopark juga harus mengembangkan dan mengoperasikan program pendidikan baik formal maupun informal di berbagai tingkatan. Beberapa cara untuk mengoperasikan 
program pendidikan di antaranya dengan ekskursi anak-anak sekolah dan guru, seminar dan kuliahkuliah saintifik (GGN-UNESCO, 2014).

Sejak tanggal 7 Oktober 2013, Geopark Rinjani Lombok telah resmi menjadi anggota jaringan Geopark Nasional Indonesia dan akan diusulkan menjadi anggota GGN-UNESCO. Dalam kawasan Geopark ini terdapat 22 situs geologi dan salah satunya adalah situs geologi yang ada di daerah Aik Berik Kecamatan Batukliang Utara Kabupaten Lombok Tengah.

Menurut Rodrigues (2012), situs geologi yang mempuyai nilai ilmiah dan estetika tinggi bisa digunakan sebagai sarana pendidikan. Nilai ilmiah dari air terjun di daerah Aik Berik diketahui dari interpretasi/pemaknaan situs geologi yang telah dipublikasikan melalui panel informasi. Adapun nilai estetika dari situs geologi ini ditunjukkan dengan banyak pengunjung yang datang ke lokasi situs geologi tersebut.

Jumlah pengunjung obyek wisata Aik Berik dalam 10 tahun terakhir menunjukkan peningkatan, meskipun pada tahun 2011-2013 mengalami fluktuasi karena kondisi jalan yang rusak (Gambar 1).

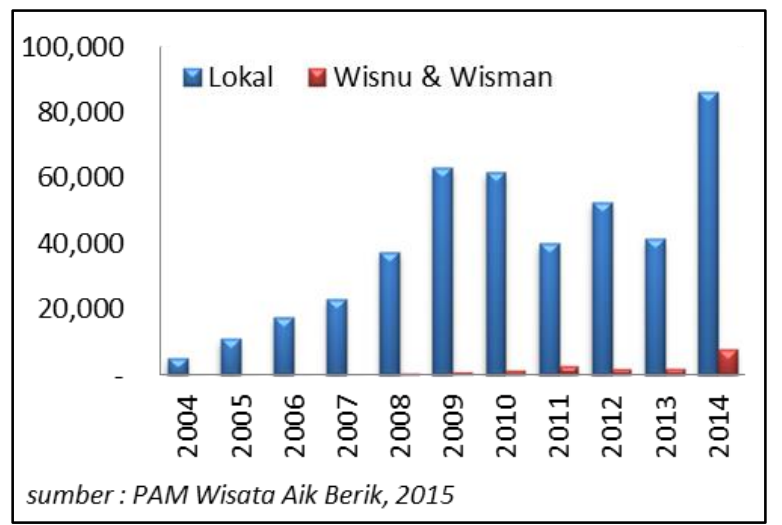

Gambar 1. Grafik Jumlah Pengunjung Obyek Wisata Aik Berik 2004-2014

Jumlah kunjungan wisatawan yang tinggi secara langsung maupun tidak langsung berakibat pada gangguan ekosistem lingkungan, bahkan dapat merusak lingkungan tersebut. Demikan juga halnya dengan kegiatan wisata pendidikan, dapat mempengaruhi kondisi ekosistem karena penyelenggaraan kegiatan ini akan lebih efektif jika dilakukan secara berkelompok dan dipandu oleh tur guide (Woo, 2014).

Permasalahan pada tingkat kenyamanan para wisatawan juga akan berkurang apabila terjadi kepadatan yang tinggi. Setiap hari tingkat kunjungan wisata tidak selalu sama. Hari libur maupun akhir pekan umumnya merupakan waktu kunjungan puncak. Sementara waktu pelaksanaan wisata pendidikan yang paling berpeluang dilakukan adalah pada hari libur khususnya hari minggu agar tidak mengganggu Kegiatan Belajar Mengajar (KBM).

Berdasarkan uraian di atas, maka perlu dilakukan penilaian terhadap daya dukung lingkungan obyek wisata Aik Berik. Hasil dari penilaian tersebut digunakan untuk merencanakan/menentukan waktu yang ideal dalam melaksanakan kegiatan wisata pendidikan.

\section{METODE PENELITIAN}

Metode yang digunakan adalah perhitungan berdasarkan rumus Cifuentes (1992) modifikasi Fandeli dan Muhammad (2009); Zacarias et.al, (2011), terdiri dari Daya Dukung Fisik (Physical Carrying Capacity/PCC), Daya Dukung Riil (Real Carrying Capacity/RCC) dan Daya Dukung Efektif (Effective Carrying Capacity/ECC). Pengumpulan data dilakukan melalui observasi/survei lapangan, studi literatur, dan wawancara.

\section{HASIL DAN PEMBAHASAN \\ 3.1.Daya Dukung Fisik (PCC)}

Dari hasil pengamatan terhadap jalur-jalur yang digunakan untuk aktivitas wisata, maka diproyeksikan luas daerah tujuan wisata Aik Berik sekitar 33,7 Ha Kebutuhan ruang pengunjung untuk kegiatan wisata pendidikan ini diasumsikan $65 \mathrm{~m} 2$ atau sama seperti kebutuhan ruang untuk berpiknik (Fandeli dan Muhammad, 2009). Dalam kegiatan wisata pendidikan dibutuhkan luas area yang cukup untuk melakukan observasi.

Berdasarkan informasi dari para guide di daerah tujuan wisata Aik Berik, waktu kunjungan untuk satu lokasi air terjun sekitar 2 jam, bila dua lokasi air terjun 3 jam, sehingga rata-rata waktu yang dihabiskan untuk satu siklus kunjungan $=(2 \mathrm{jam}+3 \mathrm{jam}) / 2=2,5$ jam. Daerah tujuan wisata Aik Berik dibuka jam 08.00 - 17.00 Wita ( \pm 9 jam per hari). Dari data-data tersebut diperoleh nilai faktor rotasi (Rf) = 9 jam $/ 2,5$ jam $=3,6$ jam

Daya dukung fisik (PCC) daerah tujuan wisata Aik Berik dihitung menggunakan rumus Fandeli dan Muhammad (2009), yaitu :

$$
\begin{aligned}
& \text { PCC = A x }(1 / \mathrm{B}) \times \mathrm{Rf} \\
& \begin{array}{ll}
\mathrm{A} & =33,7 \mathrm{Ha}=337.000 \mathrm{~m} 2 \\
\mathrm{~B} & =65 \mathrm{~m} 2, \text { jadi } 1 / \mathrm{B}=0,015 \\
\text { Rf } & =3,6 \text { jam }
\end{array}
\end{aligned}
$$

PCC $=337.000 \times 0,015 \times 3,6=18.665$ orang $/$ hari.

Hasil perhitungan PCC di atas menunjukkan bahwa luas daerah yang diproyeksikan sebagai kawasan aktivitas wisata di daerah tujuan wisata Aik Berik mampu menampung pengunjung sebanyak 18.665 orang/hari.

\subsection{Daya Dukung Riil (RCC)}

Daya dukung riil (RCC) adalah kemampuan kawasan obyek wisata untuk menampung jumlah maksimum pengunjung dengan memperhatikan beberapa faktor pembatas/koreksi sesuai dengan 
karakteristik daerah. Faktor-faktor koreksi tersebut, antara lain :

\section{a)Faktor Koreksi Kelerengan (Cf1)}

Dari hasil pengamatan lapangan terhadap jalurjalur yang digunakan untuk aktivitas geowisata, kondisi topografi secara umum relatif landai. Titiktitik lokasi yang agak curam terdapat pada lokasi yang mendekati air terjun. Berdasarkan Peta Kelerengan Pulau Lombok (BPDAS Dodokan-Moyosari, 2004), daerah tujuan wisata Aik Berik terletak pada daerah dengan nilai faktor koreksi kelerengan diperoleh dengan membandingkan nilai kondisi daerah dengan nilai maksimum kelas lereng. Nilai daerah dengan kelerengan landai adalah 40 dan nilai maksimum kelerengan berdasarkan SK Menteri Pertanian No.837/KPTS/UM/1980 adalah 100, sehingga diperoleh nilai faktor koreksi sebesar 0,6.

\section{b)Faktor Koreksi Kepekaan Tanah (Cf2)}

Menurut Balai Pengkajian Teknologi Pertanian (BPTP) NTB (2004), bentuk lahan di daerah Batukliang Utara dan sekitarnya termasuk dalam grup volkan. Jenis tanah diklasifikasikan kedalam Ordo Entisol, Inceptisol, Vertisol dan Andisol. Dari hasil pengamatan lapangan, tanah yang dijumpai umumnya berwarna coklat gelap sampai coklat dengan konsistensi gembur sampai teguh. Hal ini menunjukkan ciri-ciri dari jenis tanah Inceptisols yaitu tanah yang terbentuk dari berbagai macam bahan induk, yaitu alluvium dan koluvium, bahan volkanik dan sedimen. Inceptisols merupakan nama tanah menurut sistem klasifikasi USDA Soil Taxonomi (1975) yang padanan namanya menurut Sistem Dudal-Soepraptohardjo (1956-1961) adalah mediteran (Mega, dkk. 2010)

Jenis tanah mediteran mempunyai tingkat kepekaan kurang peka dengan nilai 45. Adapun nilai maksimum dari tingkat kepekaan tanah terhadap erosi adalah 75 . Dengan demikian nilai faktor koreksi kepekaan tanah dari daerah tujuan wisata Aik Berik dapat diketahui yaitu 0,4 .

\section{c)Faktor Koreksi Iklim}

Berdasarkan data curah hujan dari Balai Informasi Sumber Daya Air (BISDA) NTB periode tahun 2004-2014 (selama 9 tahun, data tahun 2010 tidak lengkap) jumlah bulan kering di daerah tujuan wisata Aik Berik adalah 52 bulan dan jumlah bulan basah sebanyak 54 bulan. Data tersebut digunakan untuk menghitung indeks nilai $Q=$ jumlah bulan kering/jumlah bulan basah sehingga diperoleh nilai $\mathrm{Q}$ $=0,96$. Berdasarkan klasifikasi iklim SchmidtFerguson, daerah Aik Berik mempunyai tipe iklim sedang. Nilai faktor koreksi untuk daerah dengan tipe iklim tersebut adalah 0,86.

\section{d)Faktor Koreksi Gangguan Musim Kawin Satwa}

Satwa yang ada di daerah tujuan wisata Aik Berik adalah kera hitam (Trachypithecus auratus kohlbruggie). Menurut Medway, 1970 (dalam
Febriyanti, 2008) jenis satwa ini tidak mempunyai musim kawin tertentu, kelahiran terjadi pada keseluruhan tahun. Hal ini menunjukkan bahwa keberadaan pengunjung bukan merupakan gangguan bagi proses reproduksi kera hitam.

Perhitungan daya dukung riil (RCC) menggunakan rumus Zacarias et.al, (2011) yang mengacu pada rumus Cifuentes (1992) yaitu sebagai berikut :

$\mathrm{RCC}=\mathrm{PCC} \times \mathrm{Cf} 1 \times \mathrm{Cf} 2 \times \mathrm{Cf} 3$

PCC $=$ daya dukung fisik $=18.665 \mathrm{org} / \mathrm{hari}$

Cf1 = Koreksi kelerengan $=0,6$

Cf2 = Kepekaan tanah $=0,4$

Cf3 = Koreksi Iklim $=0,86$

$\mathrm{RCC}=18.665 \times 0,6 \times 0,4 \times 0,86=3.863$ orang/hari

\subsection{Daya Dukung Efektif (ECC)}

Daya dukung efektif merupakan jumlah kunjungan maksimal dimana obyek tetap lestari pada tingkat manajemen yang tersedia. Kapasitas manajemen dibatasi oleh kriteria : jumlah petugas pengelola dan sistem pengelolaan (Purwanto, 2014). Petugas pengelola daerah tujuan wisata Aik Berik adalah pemuda/pemudi Desa Aik Berik yang bertugas sebagai pemandu lokal (guide), PAM wisata, tukang ojek dan petugas kebersihan. Menurut M. Kadran Hafifi, jumlah petugas pengelola bersifat fluktuatif, dapat bertambah terutama pada hari raya Idul Fitri maupun tahun baru masehi atau hari libur nasional lainnya. Pada hari biasa petugas pengelola berjumlah 8 orang, hari minggu 20 orang dan hari raya bisa mencapai 60 orang. Dengan kondisi petugas pengelola tersebut, maka perhitungan daya dukung efektif tidak dapat dilakukan.

\subsection{Analisis Daya Dukung}

Secara umum nilai RCC dari daerah tujuan wisata Aik Berik belum terlampaui, namun jumlah pengujung setiap hari tidak merata, terdapat waktuwaktu tertentu dimana terjadi peningkatan jumlah pengunjung. Sebagai contoh pada hari libur nasional seperti tahun baru masehi. Berdasarkan data jumlah pengunjung bulan Januari 2015, jumlah pengunjung pada tanggal 1 Januari mencapai 5.646 orang atau $146 \%$ dari RCC. Hal ini berarti nilai daya dukung riil telah terlewati. Meskipun demikian jumlah kunjungan tersebut bersifat musiman dan tidak terjadi sepanjang tahun sehingga tidak terlalu berpengaruh pada lingkungan. Selain itu, jumlah pengunjung yang melebihi batas daya dukung dapat dikelola dengan memperhatikan ukuran kelompok dan ruang (Dearden, 1997 dalam Khair, 2006).

Berdasarkan data jumlah pengunjung selama periode Januari-April 2015 (gambar 2), diketahui bahwa pada hari biasa dalam kondisi normal (tanpa hari besar/libur nasional), nilai daya dukung riil daerah tujuan wisata Aik Berik masih berada di bawah $1,9 \%$ dari RCC atau kurang dari 72 orang/hari. Pada akhir pekan, khususnya hari minggu jumlah pengunjung dapat mencapai 19,9\% dari RCC atau 767 orang/hari. 


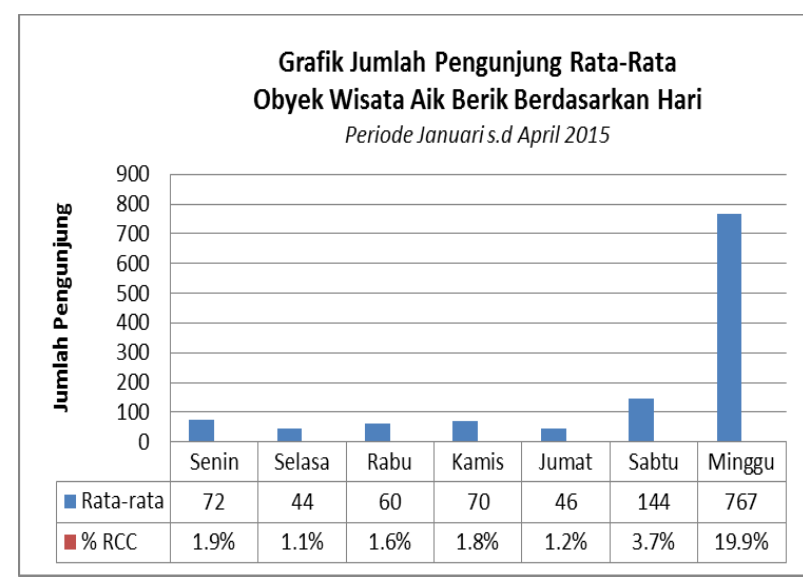

Gambar 2. Grafik Jumlah Pengunjung Obyek Wisata Aik Berik Januari-April 2015

Berdasarkan uraian di atas dapat disimpulkan bahwa penyelenggaran kegiatan wisata pendidikan di obyek wisata Aik Berik dapat dilakukan setiap hari kecuali hari besar/libur nasional. Hari minggu merupakan puncak kunjungan, namun daya dukung riil kawasan obyek wisata belum terlewati.

\subsection{Merencanakan Waktu Pelaksanaan Wisata Pendidikan}

Wisata pendidikan merupakan salah satu bentuk dari kegiatan studi lapangan. Menurut Wibowo (2013), agar studi lapangan dapat memberikan hasil yang optimal maka diperlukan berbagai persiapan diantaranya adalah menentukan waktu yang tepat untuk menyelenggarakan kegiatan tersebut.

Salah satu faktor yang mempengaruhi daya dukung kawasan wisata adalah faktor psikologis yang berhubungan dengan kenyamanan dan kesesakan areal pemanfaatan (Douglass, 1975 dalam Utari 2014). Areal yang dipenuhi pengunjung akan menurunkan tingkat kenyamanan wisatawan. Demikian juga halnya dengan kegiatan wisata pendidikan, perhatian dan ruang gerak para siswa akan terganggu jika penyelenggaran kegiatan wisata pendidikan dilakukan pada waktu ramai pengunjung.

Merencanakan waktu yang tepat dalam menyelenggarakan kegiatan wisata pendidikan dapat dilakukan dengan melihat pola kunjungan setiap hari, yaitu hari biasa (senin-jumat) dan akhir pekan (sabtu dan minggu). Pada hari biasa daya dukung riil obyek wisata Aik Berik di bawah 1,9\% dari RCC sedangkan pada akhir pekan nilai RCC dapat mencapai 19,9\% atau 767 orang/hari. Maka waktu yang ideal untuk menyelenggarakan kegiatan wisata pendidikan adalah pada hari biasa.

Beberapa cara yang dapat diterapkan antara lain dengan melaksanakan kegiatan wisata pendidikan ketika jam mata pelajaran geografi berada di akhir dari KBM. Cara lainnya adalah dengan menyelenggarakan kegiatan wisata pendidikan bersama, artinya dalam satu kali kunjungan para siswa melaksanakan tugas dari beberapa mata pelajaran sekaligus, misalnya pelajaran geografi dan biologi.

Untuk menerapkan strategi ini dibutuhkan kerjasama/kesepakatan dari para guru mata pelajaran, wakil kepala sekolah bagian kurikulum dan kepala sekolah. Para guru mata pelajaran menentukan tema materi pembelajaran yang mempunyai kesesuaian dengan obyek yang dapat diamati di lokasi kegiatan. Wakil kepala sekolah mengatur jadwal mata pelajaran sesuai dengan alokasi waktu yang dibutuhkan oleh para guru. Kepala sekolah bersedia mengeluarkan ijin pelaksanaan kegiatan pembelajaran di luar kelas.

\section{KESIMPULAN}

Daerah Aik Berik mempuyai nilai daya dukung fisik (PCC) 18.665 orang/hari dan daya dukung Riil (RCC) 3.863 orang/hari. Pada hari libur nasional/hari raya nilai RCC terlewati. Pada hari minggu nilai RCC dapat mencapai 19,9\% atau 767 orang/hari. Pada hari biasa nilai RCC masih dibawah 1,9\% atau sekitar 72 orang/hari.

Pelaksanaan wisata pendidikan di daerah tujuan wisata Aik Berik dapat dilakukan pada hari biasa (Senin-Jumat) dengan cara praktikum bersama atau dengan memanfaatkan alokasi waktu KBM yang dijadwalkan pada akhir sesi KBM.

\section{UCAPAN TERIMAKASIH}

Penulis menyampaikan terimakasih kepada PUSBINDIKLATREN BAPPENAS yang telah memberikan "Beasiswa Bappenas", sehingga penulis berkesempatan untuk melanjutkan pendidikan di Magister Ilmu Lingkungan Universitas Diponegoro.

\section{DAFTAR PUSTAKA}

Balai Pengkajian Teknologi Pertanian NTB (2004). Pewilayahan Komoditas Pertanian Unggulan di Kabupaten Lombok Tengah. Laporan Hasil Kegiatan

Fandeli. C., \& Muhammad (2009). Prinsip-Prinsip Dasar Mengkonservasi Landskap. Gajah Mada University Press. Yogyakarta

Febriyanti. N. S., (2008). Studi Karakteristik Cover Lutung Jawa (Trachypithecus auratus Geoffroy 1812) di Blok Ireng-Ireng Taman Nasional Bromo Tengger Semeru Jawa Timur. Bogor. Departemen Konservasi Sumberdaya Hutan dan Ekowisata Fakultas Kehutanan Institut Pertanian Bogor.

GGN-UNESCO. (2014). Guidelines and Criteria for National Geoparks seeking UNESCO ' s assistance to join the Global Geoparks Network ( GGN ), (Januari 2014). Diakses melalui :

http://www.globalgeopark.org/UploadFiles/2012_9_6/Geoparks_ Guidelines_Jan2014.pdf, tanggal 27 April 2015.

Khair, Uzunu. (2006). Kapasitas Daya Dukung Fisik Kawasan Ekowisata Di Taman Wisata Alam (TWA) Sibolangit Kabupaten Deli Serdang. Tesis. Sekolah Pasca Sarjana Universitas Sumatera Utara. Medan

Kusumabhrata, Y., \& Suwardi, S. (2012). Indonesia Menuju Jaringan Geopark Dunia. Geomagz, 2(1), 18-25.

Mega, I.M,. Dibia, I.N,. Adi, I.G.P.R,. Kusmiyarti, T.B., (2010). Klasifikasi tanah dan Kesesuaian lahan. Buku Ajar. Program Studi Agroekoteknologi Fakultas Pertanian Universitas Udayana. Denpasar. 
Hardoyo ,D., Muhammad, F., dan Taruna, T. (2016). Perencanaan Kegiatan Wisata Pendidikan Dalam Kawasan Geopark Rinjani Lombok Berbasis Daya Dukung Lingkungan (Studi Daerah Aik Berik). Jurnal Ilmu Lingkungan,14(2),103-107, doi:10.14710/jil.14.2.103-107

Purwanto, S,. 2014. Kajian Potensi dan Daya Dukung Taman Wisata Alam Bukit Kelam Untuk Strategi Pengembangan Ekowisata. Tesis. Bogor. Sekolah Pascasarjana Institut Pertanian Bogor.

Rodrigues, J., (2012) : Pedagogical Geosciences tools to explain Naturtejo Geopark in both non-formal and formal environments. Publikasi Seminar Paleontologi Zaragoza. Diakses melalui :

www.naturtejo.com/ficheiros/conteudos/files/Rodrigues 2012.pdf, tanggal 10 April 2015

Utari, W. D., (2014). Daya Dukung Ekologis dan Psikologis Ekowisata di Kebun Raya Cibodas. Tesis, Sekolah Pascasarjana Institut Pertanian Bogor, Bogor. Diakses melalui

http://repository.ipb.ac.id/handle/123456789/73030,

tanggal 5 Mei 2015

Wibowo. Y., (2013). Bentuk-Bentuk Pembelajaran Outdoor. Jurusan Pendidikan Biologi FMIPA UNY. Diakses melalui : http://id.scribd.com/doc/163644002/Bentuk-BentukPembelajaran-Outdoor\#scribd, tanggal 10 Desember 2015

Woo, K.S., (2014). Qualification and prospect of national and global geoparks in Korea. Journal of the Geological Society of Korea, 50(1), 3-19. doi: 10.14770/jgsk.2014.50.1.3

Zacarias, D.A., Williams, A.T., Newton, A., (2011). Recreation carrying capacity estimations to support beach management at Praia de Faro, Portugal. Applied Geography, 50(1), 10751081. doi: 10.1016/j.apgeog.2011.01.02. 